\title{
Assessment of Physical Vulnerability in Santo Domingo De Heredia, Costa Rica, Central America
}

\author{
Jonnathan Reyes Cháves', Mario Fernández Arce², Daniel Solís ${ }^{3}$, \\ Rafael Bolaños Villalobos ${ }^{4}$ \\ ${ }^{1}$ Escuela de Geografía, Universidad de Costa Rica (UCR) \\ ${ }^{2}$ Preventec-Universidad de Costa Rica (UCR), Escuela de Geografía-UCR and Centro de Investigaciones en \\ Ciencias Geológicas-UCR \\ ${ }^{3}$ Preventec-UCR \\ ${ }^{4}$ Casa de la Cultura de Santo Domingo de Heredia \\ Email: daniel.solis@ucr.ac.cr
}

Received July 2014

\section{Abstract}

This work assesses the physical vulnerability of the Santo Domingo Canton in the province of Heredia in Costa Rica. We evaluate the vulnerability of areas located in high risk zones as well as the structural resistance of structures of the canton and then combine them to obtain an index of Physical Vulnerability. Most of the communities in high risk areas in this Canton have not been properly identified and mapped. This identification and mapping will enhance the management of disaster risks, reduce the infrastructure vulnerability and protect vulnerable families in there. We created an index ranging between 0 and 1 for each indicator of physical vulnerability (human settlements in areas of high risk and structural resistance) and another similar index resulting from the combination of vulnerability information from both indicators. The greater part of the territory of Santo Domingo has low physical vulnerability but there are critical sites in the West and the East of the canton.

\section{Keywords}

Vulnerability, Santo Domingo, Heredia, Disasters, Prevention, Costa Rica

\section{Introduction}

According to Wilchez [1], human vulnerability is divided into 11 components, namely: Natural, Physical, Social, Economic, Technical, Institutional, Political, Educational, Ecological, Ideological and Cultural. In this paper we shall confine ourselves to only the Physical Vulnerability in the canton Santo Domingo (Figure 1). Physical Vulnerability is the location of human settlements in areas of disaster risk and the low resistance of the structures situated in such settlements. Such vulnerability is manifest by deficiencies of the physical structures to res- 


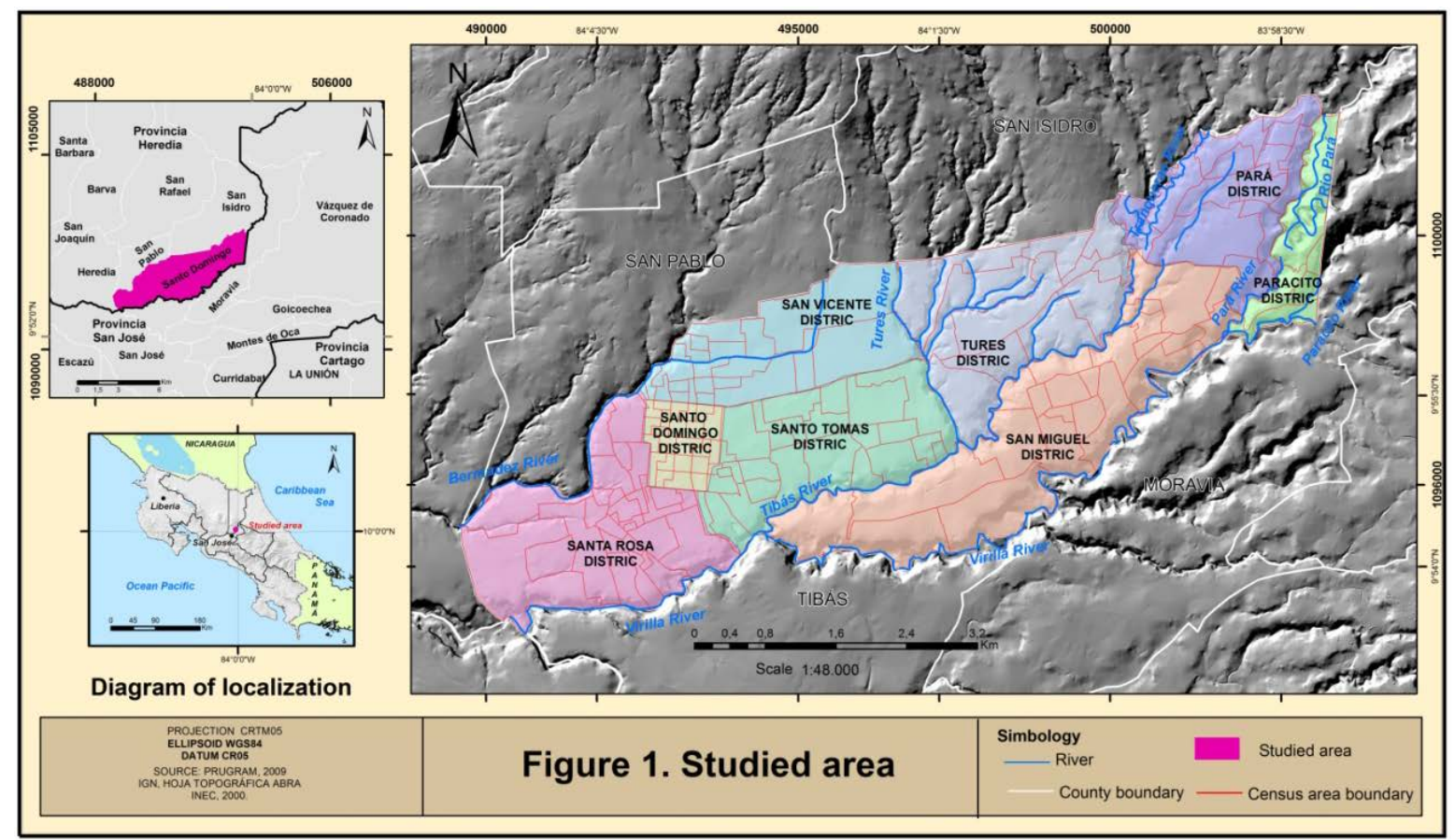

Figure 1. The territory of Santo Domingo, its districts and its Minimum Geostatistical Units (small areas within the districts).

ist the impacts from the disaster threats.

Those who choose to build homes in high-risk areas usually do it not by desire, but because lack of options, primarily because their purchasing power is below the price of land in more secure and stable areas. And they often end up there by various means including illegal invasions, political patronage or bad business practices in which illegal constructors do not have the minimum liability against its customers. Residences in these areas are highly vulnerable not only economically but in many aspects.

This research was carried out because there are vulnerable neighborhoods in Santo Domingo that have high disaster risk and are often impacted by threats. The case of Barrio Fatima is known but without a specific study, it is difficult to know all of those neighborhoods with high vulnerability index. With the passage of time it has been proven that disasters are increasing instead of decreasing, and this is due both to the increase in the population, resulting in increased exposure to threats, and the increase of poverty.

Therefore, we must clearly identify and measure indicators of Physical Vulnerability in Santo Domingo, in order that work to minimize such risk factor can begin and most importantly, to protect the vulnerable from the impact of the threats. We want our results to affect both the development of the canton and to promote the safety and well-being of the population. We want this investigation to promote mitigation through non-structural actions, codes, legislation, compulsory observation of precautions, appropriate design and calculation of structures. But we aspire to something much better: the prevention of disaster which would necessarily include the relocation of the families which today occupy at-risk sites where their lives and property are in danger.

To measure the spatial distribution of the Physical Vulnerability of Santo Domingo we evaluated 2 indicators: exposed human settlements and resistance of structures. For this, literature review was necessary and field work to identify areas highly exposed to different threats [2] [3]. Information on indicators of vulnerability was used to make indexes of value between 0 and 1 .

The most important findings include the identification of Physical Vulnerability in the West of the canton, where floods and landslides are a threat to the developments. We also found clear evidence that exposure to threats and poverty occurs together in the most vulnerable communities of Santo Domingo de Heredia.

\section{Antecedents}

Although Santo Domingo is among the cantons with higher index of human development in Costa Rica, it also 
has poor neighborhoods that have origins in the industrialization era. Indeed, in the middle of the $20^{\text {th }}$ century, Costa Rica, like the others countries of Central America, entered into the era of industrialization after facing a very critical period for the international sale of the monoculture product coffee, who's price was devalued since the crises of 1929 and World War II. The two economic crises produced a large loss of wages within of coffeeproducing areas, mainly located in the Central Valley of Costa Rica. When Costa Rica started this process of crop substitution and establishment of manufacturing industries, the population began to migrate from the countryside to the cities and it is in this context that a number of slums and marginal urban areas in the cantons in the central of the country such as Monte Carmelo. In addition to the arrival of many rural families in urban areas, new manufacturing businesses were established in the country like in much of Central America as part of the Central American Common Market which was created with the stated purpose of sending farmers to factory jobs.

In 1960, the North-West border of Santo Domingo had a large and very poor neighborhood of native families who had no homes and could not afford rent on homes therefore, built slums and lived without electricity and drinking water along with other problems at that time. In this environment there was constant violence, drugs, and abuses of all kinds. The image that was projected to the rest of the community was not very exemplary in addition to the typecasting of these marginal groups.

In the early 1970's the "Damas Israelitas (Israeli Ladies)", a group of Israeli women residing in Costa Rica, became concerned with the condition of these families and started very commendable work for the eradication of this precarious neighborhood involving participation of community organizations and local government. Existing dwellings with some exceptions were rebuilt four decades ago so many of these families are able to have better housing conditions, although the problems of slums still persist.

Previous studies have provided evidence for the presence of vulnerabilities in Santo Domingo. Fernández et al. [4] investigated the floods generated by overflows of the Rio Bermudez and reported that several communities of Santo Domingo were severely affected by floods in 1999 and 2010. In 2012, the study called "Determination of the risk of disaster in Santo Domingo de Heredia" began. Conducted between 2012 and 2014, this study led to a comprehensive analysis of the vulnerability in the canton. Two important works related to the vulnerability of the population of Santo Domingo came from this project. One of them is Reyes and Fernández [5] in which they presented the results of an analysis of maximum human vulnerability in the canton and shown that such vulnerability is greatest in the areas where the proximity of the threat and poverty are combined. Another important work is that of Reyes et al. [6] which consists of a comprehensive study of the risk of disaster including natural and anthropogenic threats as well as a comprehensive analysis of vulnerability. Twenty five indicators of vulnerability were analyzed in this study and a map of vulnerability for the entire canton was produced. That map shows that there is increased hazard vulnerability in the south and west areas of the canton.

\section{Methology}

For every Minimum Geostatistics Unit (MGU) of Santo Domingo (140 in total) we measured 2 indicators of Physical Vulnerability as shown in Table 1. Field studies and data from the 2000 Census [7] were used to create a score of value between 0 and 1 , with a higher value indicating greater vulnerability.

Once the index values were calculated, they were summed, re-indexed on a new scale of 0 to 1.00 , assigned to each of the UGM and imported to a system of geographic information (GIS) as a data layer. These values were then stratified using the method of natural breakings and displayed on maps. A comprehensive vulnerability index score was created on surface through the UGM to inhance the display.

\section{Results}

\subsection{Human Settlements in High Risk Zones}

The distribution of human settlements located in areas of risk in Santo Domingo is shown in Figure 2. Critical sites are the neighborhoods Fatima, La Rinconada, San Martín, RIncón de Ricardo, the extreme southwest of Santo Tomás, and La Presa in the district Paracito.

Fatima and Monte Carmelo (next to Fátima) communities are located on the southern slope of the Río Bermúdez, which is the boundary between the cantons San Pablo and Santo Domingo. For many years these neighborhoods did not suffer flooding because the river flow was small but with the increase of the urbanization process and the consequent increase of the waterproofing of soils, the once insignificant River now floods fre- 
Table 1. Indicators of Physical Vulnerability.

\begin{tabular}{cc}
\hline Type of Vulnerability & Indicators \\
\hline Physical Vulnerability & Human Settlements in High Risk Areas \\
& Structural Resistance \\
\hline
\end{tabular}

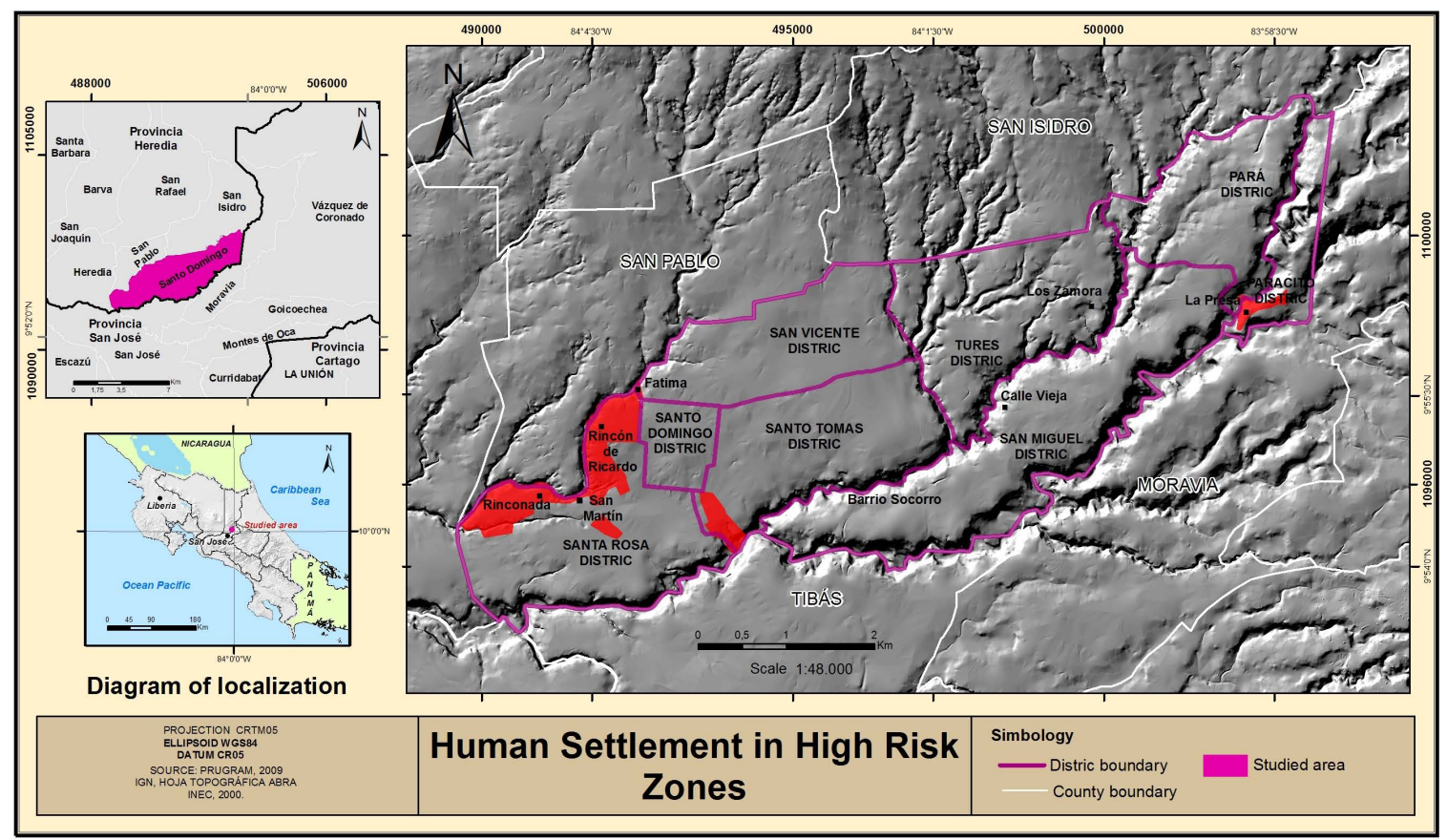

Figure 2. The red areas correspond with the human settlements in zones of high risk in Santo Domingo.

quently. According to Fernández et al. [4] this neighborhood was severely affected by floods in 1999 and 2010 and about 30 homes were declared uninhabitable. But even today families remain in this area of high risk for flooding and where there is evidence of landslide. During walks through this neighborhood we observed collapses in the backyard of some houses, cracks in the ground in front of the houses and cracks both on the walls and the floors of them generated by the soil instability and the inadequate channeling of waters. In houses declared uninhabitable several years ago families still lived despite the great risk to life.

Fátima was affected by the large amount of water that now reaches the Río Bermúdez which did not exist a few decades ago. The water level now rises beyond the limits to which communities have adapted to and the people there can no longer live with the risk in Fátima. Physical vulnerability has no doubt aggravated the economic vulnerability of this community because the floods of the river causes them great economic losses. The only alternative to this community is their total relocation and conversion of this space to a protected forest area.

There are several houses at the foot of small vertical slopes made of soft clay soil which emit lots of water during the rainy season and where small landslides occur in the form of slices or wedges of soil. This could evolve towards one large landslide and several homes could be affected and there could even be deaths. Along the entrance street to Barrio Fatima one can see a wall being subjected to great pressure from the hilside behind it. As a result of such pressure, the wall is deformed curved and fractured in its central section. This wall represents a danger for all those who enter or leave the Fátima neighborhood. The sudden collapse of the wall could be deadly for people who pass in front of it.

In Rincón de Ricardo, the problem is that some settlements have been located in a small plain of the Bermudez river. Before July 2010, about 5 families with very limited economic resources lived here. In July 2010 the river overflowed and flooded the plain destroying 4 of 5 houses. Only one house withstood the flood and it still remains inhabited and is exposed to floods. Something similar happens in Barrio San Martín and La Rinconada. There people live on the banks of the Bermúdez river, in poorly constructed houses and in very poor condition. La Presa is another settlement near a river. 
In the extreme southwest of Santo Tomás, there is a group of homes and commercial establishments located very close to a pipeline carrying fuel. In this case the minimum distance that is set for this type of structure is not observed and those who live in those houses and working in the commercial establishments are therefore exposed to a potential incident involving the pipeline. In other sections of the pipeline, near Santo Domingo, there have already occurred serious incidents that have caused economic losses and caused much fear in the people who live near these sites [2].

\subsection{Structural Resistance}

The other indicator within the physical vulnerability index is the resistance of structures to hazards for which we used the variable from the Census 2000 called Condition of Housing. Using this variable we first obtained a percentage of homes in poor condition and then an index from 0 to 1 for each one of the MGU. As you can see in Figure 3, the structural resistance in Santo Domingo is very good. The index of vulnerability for this indicator is less than 0.48 in approximately $80 \%$ of the territory, which reveals that the vast majority of the structures of the canton are strong and resilient. This explains why earthquakes cause little damage in the canton.

Low resistance of structures lies in the areas of brown and red. The red zone of San Vicente is Fatima, an area with low quality housing. La Zamora appears as an area of very high physical vulnerability because that area is poorly conditioned for living in. Many families lived there in conditions of great poverty in slums unfit for living. Dwellings were not real houses but places to protect the people from Sun and rain. Very high UGM values in red (Para and Paracito) correspond to areas where the state of the housing is not good and therefore the people who live in these houses are physically vulnerable.

Brown areas corresponding to high MGU values are either poor neighborhood or rural areas with homes in bad condition. The one located in San Vicente has an illegal settlement built on a narrow strip along the route between Santo Tomas and San Vicente (Figure 4). The land is municipal property and has been occupied by families for decades.

\subsection{Physical Vulnerability}

By combining information from the two previously analyzed indicators we can obtain a map of Physical Vulnerability for Santo Domingo de Heredia (Figure 5). That map gives a clear idea of the sites of greatest physical vulnerability resulting from exposed settlements and the structural resistance of the housing.

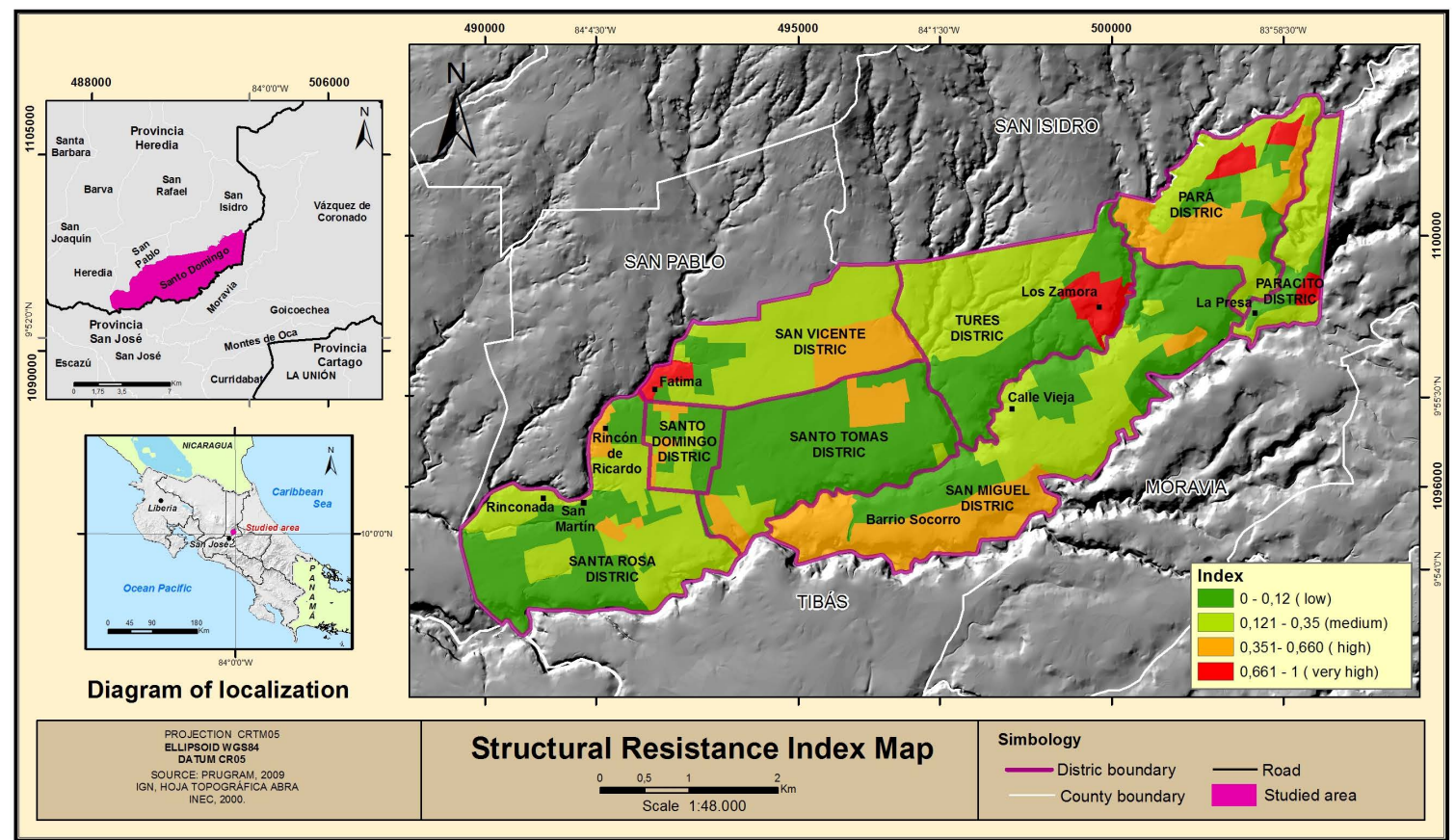

Figure 3. Map of Structural Resistance for Santo Domingo. 


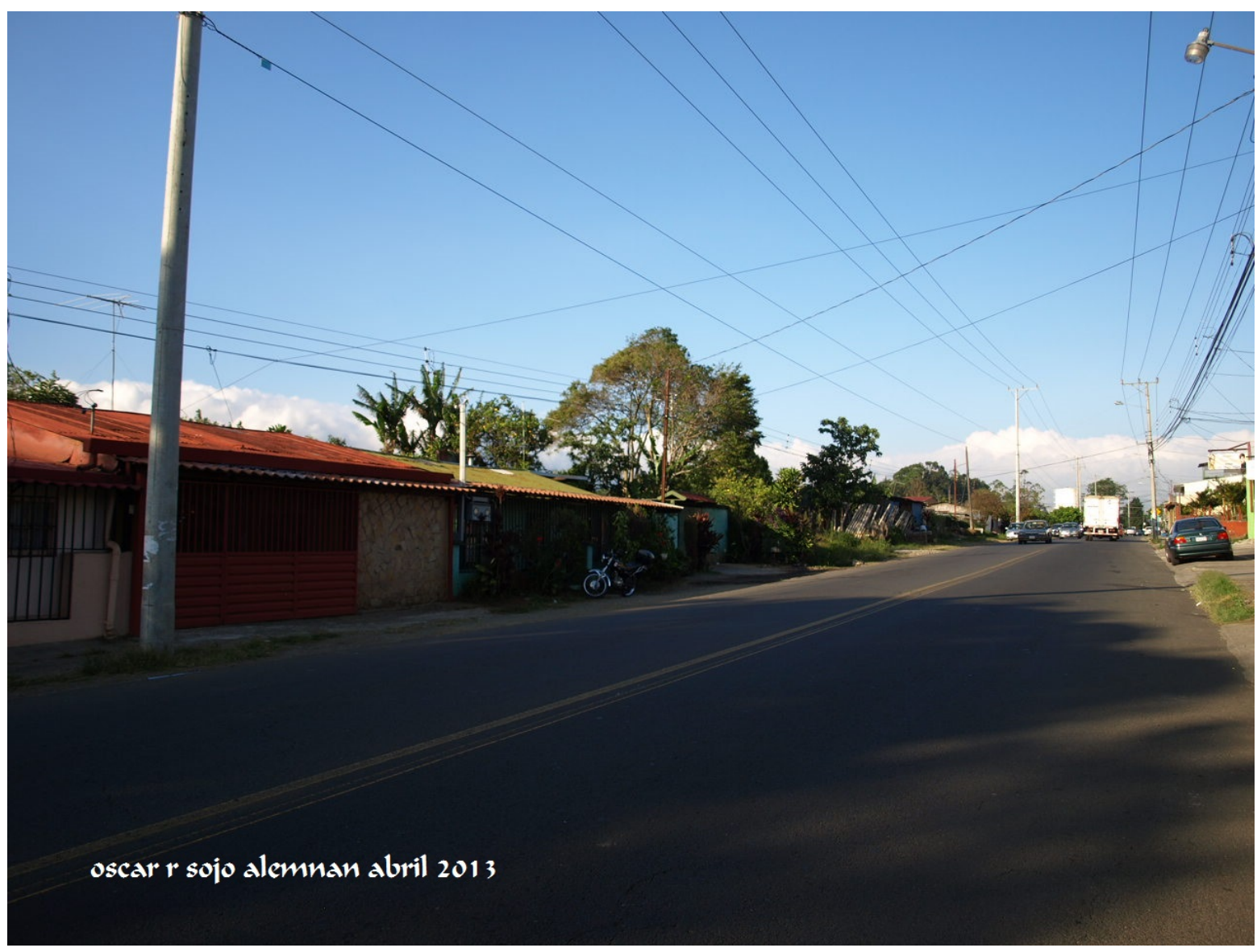

Figure 4. Part of an illegal settlement in San Vicente, Santo Domingo.

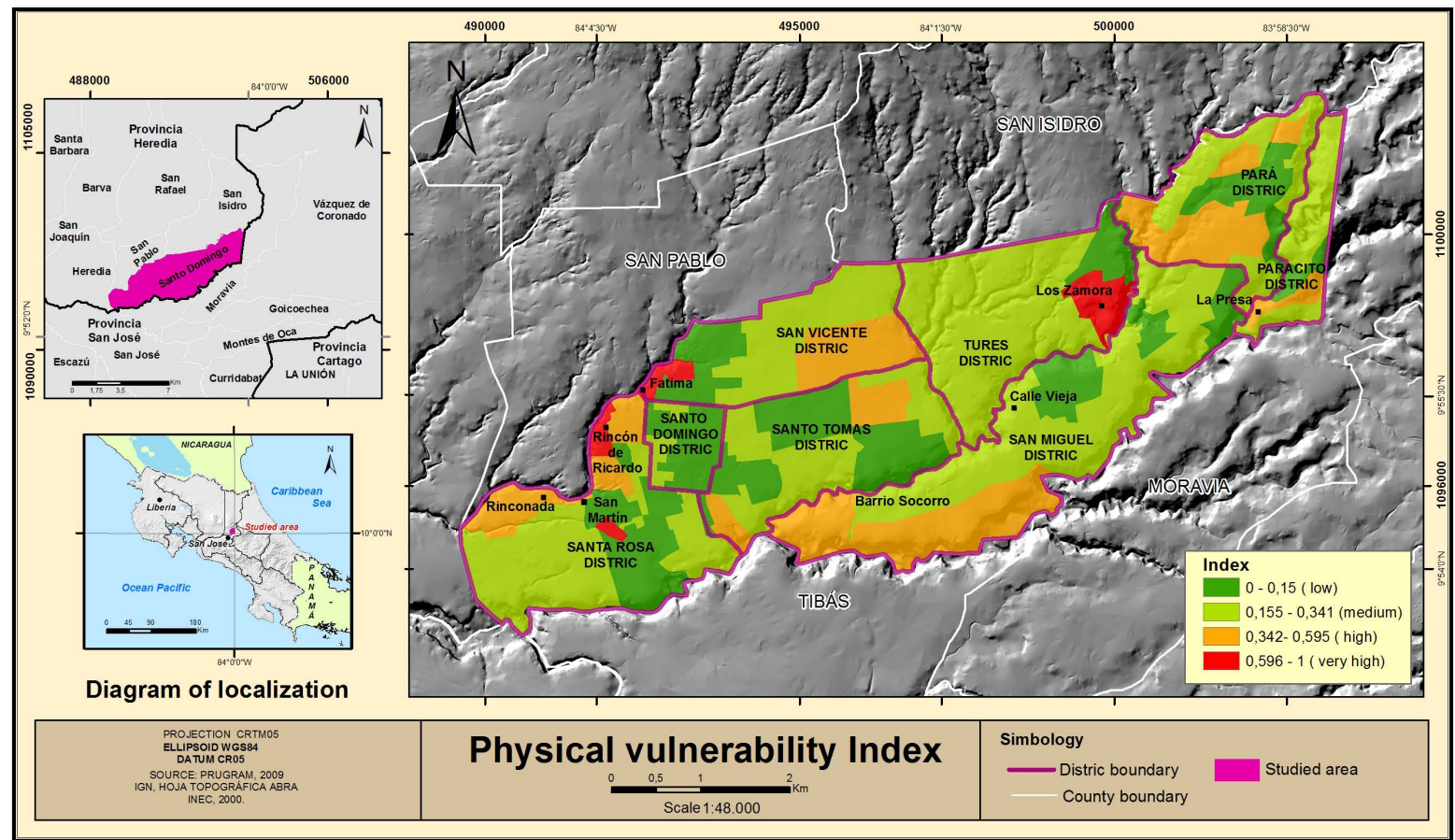

Figure 5. Map of Physical Vulnerability of Santo Domingo. 
The first thing that stands out on the map is that the physical vulnerability in the canton is extremely low. The greater part of the territory of Santo Domingo is covered by areas of green color which represents the low and medium vulnerability. The most critical sites are undoubtedly the sector of Fátima-San Martín, where there are inhabited floodplains and neighborhoods close to the rio Bermúdez. La Zamora shows as red because at the time of this investigation this settlement was the main slum of Santo Domingo and La Presa is a inundated zone. There are vulnerable families of low income in most of the critical areas that have very few resources to resist to the flooding threats. But there is little that can be done to resist the threat by floods there; what local authorities should do to avoid emergencies in those high risk zones is to relocate the families living there.

The area in brown in the West of the Santo Tomás district, and southwest of the San Miguel District, represents both the exposure to the pipeline and the low structural strength of the housing there. The remaining areas of Brown are basically due to houses in poor condition of rural areas. Although those zones have high vulnerability for resistance, they are not exposed to threats so their situations are not critical.

\section{Conclusion}

Human settlements in zones of high risk and the structural resistance contribute significantly to the overall physical vulnerability of Santo Domingo. The critical areas are in the west and east extremes of the canton. In the west the human settlements location in high risk areas is the main contributer to the physical vulnerability. In the east the major vulnerability is due to the structural resistance. Approximately $70 \%$ of the territory of Santo Domingo has Physical Vulnerability between very low and average and 30\% between high and very high. The area's major vulnerability is in the west and is due to exposure to flooding. Observations in Barrio Fatima, Monte Carmelo, Rincón de Ricardo, San Martín, La Rinconada, the Western End of Santo Tomás and La Presa reveal conditions of high risk for residents of such neighborhoods. Families located in Fátima are exposed to floods and landslides and should be relocated urgently.

\section{Acknowledgements}

Thanks to Dennis Lindwall for improving the style and grammar of this manuscript.

\section{References}

[1] Wilchez, G. (1993) Vulnerabilidad Global. In: Maskrey, Los Desastres no son Naturales, La Red, Tercer Mundo.

[2] Reyes, J. and Fernández, M. (2013) Amenazas Tecnológicas en Santo Domingo de Heredia. Revista de Salud Ocupacional HOY, 5, 23-24.

[3] Reyes, J., Fernández, M., Grineski, S. and Collins, T. (2014) Natural Hazards in Santo Domingo de Heredia, Costa Rica, Central America. Natural Science, 6, 121-129. http://dx.doi.org/10.4236/ns.2014.63017

[4] Fernández, M., Borges, J., Melendez, G., Mora, F., Mora, J. and Muñoz, C. Análisis de Gestión de Riesgo de Inundación en la Ciudad de Santo Domingo de Heredia. In: Adamson, M., Ed., 266-286.

[5] Reyes, J. and Fernández, M. (2014) Maxima Vulnerabilidad Humana en Santo Domingo de Heredia. Submited to Reflexiones.

[6] Reyes, J., Fernández, M., Grineski, S. and Collins, T. (2014) Spatial Analysis of Disaster Risk in Santo Domingo de Heredia, Costa Rica, Central America. Journal of Geography and Geology, in Press.

[7] Instituto Nacional de Estadística y Censo (INEC) (2000) X Censo Nacional de Población y VI Censo Nacional de Vivienda 2011. 